Doi: $\underline{\text { dx.doi.org/10.17921/2525-5320.2016.260-262 }}$

\title{
USO DA INTERNET E APRENDIZAGEM: O QUE PENSAM OS ALUNOS DO ENSINO MÉDIO?
}

\author{
Eliza Adriana Sheuer Nantes* - UNOPAR \\ Antonio Lemes Guerra Junior*- UNOPAR \\ Juliana Fogaça Sanches Simm* - UEL
}

Palavras-chave: Tecnologia. Internet. Aprendizagem. Percepção Discente.

\section{INTRODUÇÃO}

Já há algum tempo, muitas pesquisas vêm sendo realizadas no intuito de avaliar o avanço da internet e de suas ferramentas nas diferentes esferas de atividade humana, incluindo a escolar. A chamada Sociedade da Informação, resultado da acelerada disseminação tecnológica na contemporaneidade, agrega sujeitos que, em certa medida, se distanciam de práticas tradicionais de aprendizagem. Estudiosos como Lévy (1999), Moran (2012) e Rojo (2013), por exemplo, dialogam ao apontarem para uma mesma reflexão: a de que a grande quantidade de informações disponível no ciberespaço possibilita ao individuo acessá-las de qualquer lugar, incluindo da escola, até mesmo sem permissão. E nesse grande universo, como sugere Xavier (2011), eclode um conjunto de plurilinguagens capazes de alterar o modo como as pessoas lidam com esses dados. Daí a necessidade de se avaliar como os estudantes se comportam nesse contexto, verificando o que pensam sobre o impacto da internet em sua rotina de aprendizagem.

O objetivo central deste trabalho é aferir o nível de percepção de um grupo de estudantes do Ensino Médio quanto ao impacto da internet e das ferramentas que ela oferece em sua prática escolar, especialmente nas atividades de estudo, de busca de informações e, inclusive, na memorização de conceitos, de modo a evidenciar como se comportam enquanto sujeitos aprendizes na era digital.

\footnotetext{
*E-mail: eliza@unopar.br

*E-mail: junior.guerra@hotmail.com

*E-mail: julianafogacasanches@gmail.com
} 


\section{MATERIAL E MÉTODOS}

Sob um caráter predominantemente qualitativo, a pesquisa envolveu, como sujeitos de investigação, 70 alunos do Ensino Médio de duas escolas da cidade de Londrina-PR. Para a coleta de dados, recorreu-se ao instrumento questionário, cujas perguntas propiciaram aos estudantes abordados reflexões baseadas em itens como: tempo de uso diário da internet; presença da internet em suas atividades de estudo; recebimento de incentivo - escolar ou familiar - para o uso da internet; tipos de informações buscadas; impacto da internet na sua aprendizagem; relevância da memorização de informações; e impacto das ferramentas de busca nesse processo. As respostas dos alunos, a partir dos enunciados por eles elaborados, foram categorizadas considerando-se aproximações e distanciamentos em suas percepções. Posteriormente, o conjunto de informações foi analisado quanto ao seu conteúdo, permitindo a visualização do posicionamento apresentado pelos estudantes.

\section{RESULTADOS E DISCUSSÃO}

Por meio do questionário, observou-se que 98,5\% dos alunos utilizam a internet diariamente, sendo que, desses, $42 \%$ passam 5 horas ou mais conectados à rede, principalmente com atividades ligadas a práticas de lazer e estudo ( $97 \%$ dos respondentes), por meio de sites como Wikipédia e Google. Quanto à memorização de conceitos, $61,5 \%$ dos estudantes consideram importante essa prática, principalmente no que diz respeito a regras ortográficas, vocabulário e significados de palavras. No entanto, 4,5\%, consideram desnecessário memorizá-los, pois, caso precisem, acessarão o Google. Isso se relaciona com a informação de que $78 \%$ dos discentes afirmam acessar essa ferramenta para os estudos, apontando para uma forte evidência de que poucos utilizam a internet com a finalidade de aprender de fato. Por fim, chamam atenção respostas que indicam que os alunos fazem uso desses recursos a fim de poupar tempo e esforço cognitivo.

\section{CONCLUSÃO}

A partir dos resultados, chegou-se à conclusão de que a onipresença dos recursos digitais, especialmente a internet, na prática escolar dos alunos, afeta a sua percepção relacionada à busca de informações e à memorização de conceitos, 
atividades inerentes ao contexto da aprendizagem. As virtualidades disseminadas na contemporaneidade geram, portanto, relativo grau de dependência tecnológica desses jovens, o que revela, ainda, uma transformação no processo de aprender.

\section{REFERÊNCIAS}

BARBA, C.; CAPELLA, S. (Org.). Computadores em sala de aula: métodos e usos. Porto Alegre: Penso, 2012.

LÉVY, P. Cibercultura. São Paulo: Editora 34, 1999.

MATOS, E.L.M.; PINEL, N. Novas linguagens, novos desafios: a internet no contexto escolar. In: TORRES, P.L. (Org.). Complexidade: redes e conexões na produção do conhecimento. Curitiba: SERNAR-PR, 2014, p. 131-142.

MORAN, J.M. Novas tecnologias e mediação pedagógica. Campinas: Papirus, 2012.

ROJO, R. Escol@ conectada: os multiletramentos e as TICs. São Paulo: Parábola, 2013.

SPARROW, B. et al. Google effects on memory: cognitive consequences of having information at our fingertips. Science, v.333, p.776-778, 2011.

XAVIER, A.C. Retórica digital nas redes sociais. In: XAVIER, A.C. et al. Hipertexto \& cibercultura: links com a literatura, publicidade, plágio e redes sociais. São Paulo: Respel, 2011. p. 27-60. 